\title{
PELIGROSIDAD, VULNERABILIDAD Y RIESGOS EN LA COSTA NORTE DE LA CIUDAD DE MAR DEL PLATA, ARGENTINA. CASO DE ESTUDIO: PLAYAS DANILO Y SUN RIDER
}

\section{HAZARD, VULNERABILITY AND RISKS IN THE NORTHERN COAST OF MAR DEL PLATA, ARGENTINA. CASE STUDY: DANILO AND SUN RIDER BEACHES}

Lic. Melisa Pontrelli Albisetti

Miembro del Grupo de Estudios de Ordenación Territorial

Departamento de Geografía

Facultad de Humanidades

Universidad Nacional de Mar del Plata

\section{Resumen}

El siguiente trabajo plantea que el espacio geográfico litoral puede ser concebido como un espacio problema por la coexistencia de problemas ambientales y conflictos sociales. Los aspectos de interés para la planificación se manifiestan con impactos negativos. Entre éstos últimos, se destacan aquellos vinculados con condiciones de amenaza y vulnerabilidad donde los mismos se manifiestan cuando interacciones no planificadas del medio social sobre el medio natural, derivan en situaciones de riesgo para el hombre, sus obras y demás bienes del entorno. Este es el caso de las playas Danilo y Sun Rider, en la costa norte de la ciudad de Mar del Plata.

Palabras claves: peligrosidad; vulnerabilidad; riesgos

\begin{abstract}
This paper studies that the coastal area can be conceived as a problem by the coexistence of environmental and social conflicts. Interest aspects of planning are manifested as adverse impacts. Among the latter, we emphasize those related to threat and vulnerability conditions where these interactions are manifested when unplanned social environment on the natural environment, resulting in situations of risk to society, it work and other property of the environment. This is the case of Danilo and Sun Rider beaches on the northern coast of Mar del Plata.
\end{abstract}

Key words: hazard; vulnerability; risks 


\section{Introducción}

La costa norte de la ciudad de Mar del Plata se caracteriza por la presencia de acantilados y playas de reducida extensión. La mayoría de ellas se dedica al turismo de playas y a la práctica de deportes acuáticos y náuticos. El área de análisis, como también gran parte del sector, se ve afectado por varias amenazas o peligros, entre ellos, la erosión marina y la contaminación de sus aguas por vertidos urbanos. Resulta llamativa a simple vista, la escasa superficie de las playas en relación a las de la zona sur de la ciudad. La textura de la arena, el color del agua y las estructuras de acantilados, generan un paisaje único que, con el paso de los años, se ha ido degradando por la conjunción de diversos factores.

La erosión costera ha sido una amenaza al sector desde la construcción del puerto marplatense a principios del siglo XX y se agravó por la implementación de obras de defensa costera que no funcionaron como tal. Algunas de esas obras de protección fueron las escolleras, estructuras de roca dispuestas en forma perpendicular a la línea de costa. Su función principal es frenar la erosión; aunque cabe destacar que detienen el proceso erosivo a medias, ya que hacia el sur de la misma se acumula arena, pero en el lado norte, la erosión se potencia. En suma, esta tecnología no ha sido la adecuada para afrontar una de las problemáticas ambientales más importantes que ha padecido el sector desde hace tiempo.

Otra amenaza en esta área es la contaminación del agua de mar por el vertido de líquidos cloacales provenientes de la planta de pretratamiento de efluentes domiciliarios (Pérez Guzzi, 2006). A ello se suman algunos desagües pluviales que también vierten sus aguas y residuos en la playa y costa, desmejorando su balneabilidad y originando conflictos de usos.

Este espacio litoral también es usado y disputado por disímiles actores sociales: bañistas, surfistas, kayakistas, club de surf "Sun Rider", concesionarios privados, la Municipalidad de Gral. Pueyrredón y la provincia de Buenos Aires, entre otros. Cada uno de ellos tiene su racionalidad e intereses, algunos de ellos contrapuestos.

Las problemáticas ambientales generan diversos riesgos que se manifiestan en el sector. En este concepto "se debe incluir el daño físico esperado y las víctimas o pérdidas económicas, los factores sociales, organizacionales e instituciones, relacionados con el desarrollo de las comunidades" (Cardona 2001:5). Los riesgos para la población y sus bienes son inherentes a la salud y a las posibles pérdidas materiales en un futuro, revierten varios de los procesos presentes.

\section{Métodos y recursos}

a) Selección de técnicas de análisis a aplicar en el área de estudio: cadenas causales (Monti, 2007); clasificación de elementos expuestos (Monti, 2007).

b) Fotografías personales, imágenes satelitales y entrevistas. 


\section{Área de estudio: Playas Danilo y Sun Rider}

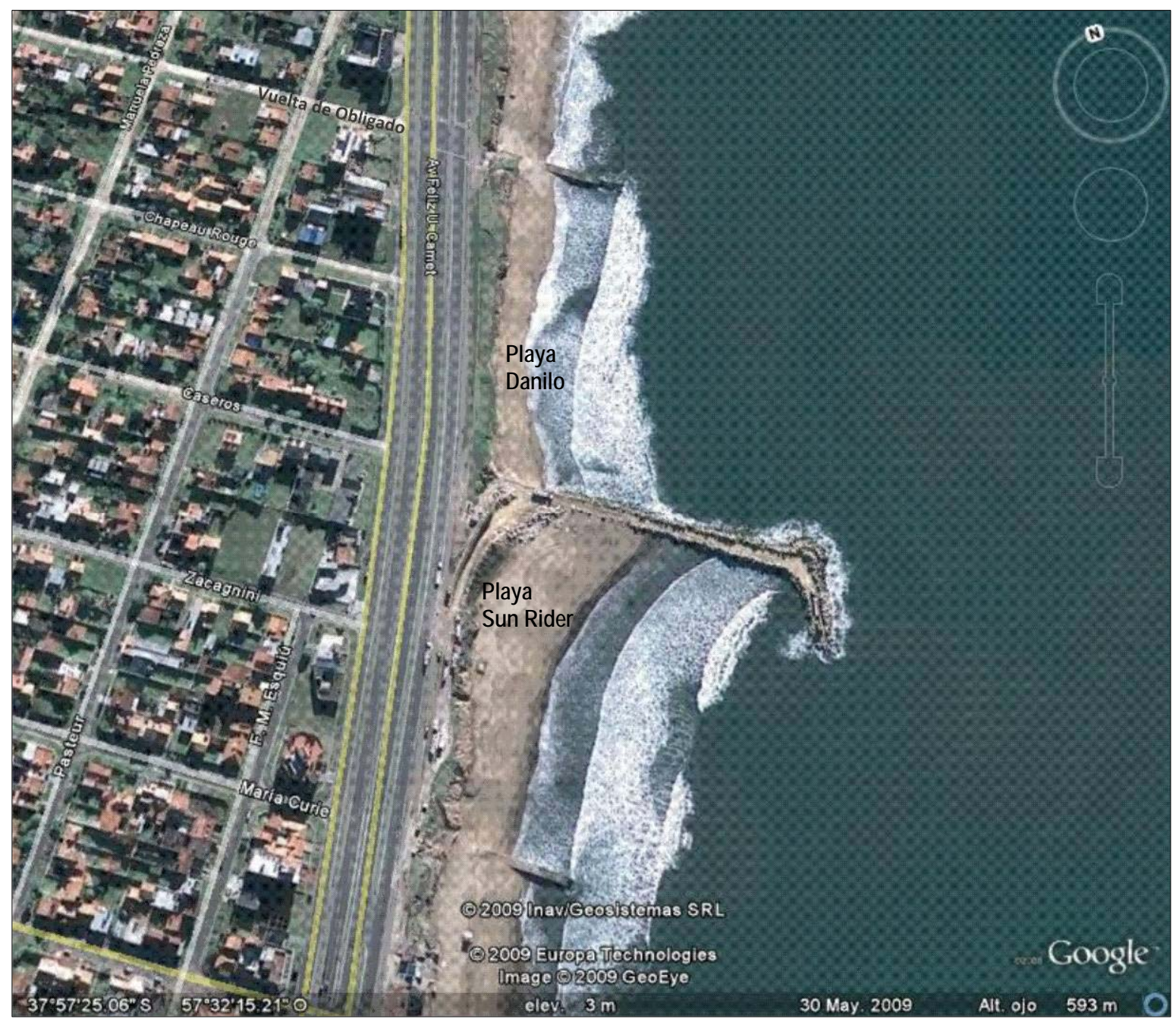

Imagen 1. Localización del área de estudio.

Fuente: Google Earth. Fecha de consulta: 2/12/2010

\section{Peligrosidad, vulnerabilidad y riesgos en el área}

El conjunto de peligrosidad, vulnerabilidad y riesgos se manifiestan en ambas playas, algunos con mayor incidencia en una que en la otra. Existen amenazas en la zona de estudio, las cuales son la antesala de cualquier evento peligroso. Las principales amenazas tanto de la Playa Danilo como de Sun Rider se encuentran ligadas a la erosión costera y paradójicamente, a las soluciones brindadas por parte de las autoridades provinciales con respecto a dicha problemática.

El concepto de amenaza se refiere a un peligro latente o factor de riesgo externo de un sistema o de un sujeto expuesto. Se puede expresar en forma matemática como la probabilidad de exceder 
Revista Geográfica Digital. IGUNNE. Facultad de Humanidades. UNNE. Año 8. № 16. Julio - Diciembre 2011. ISSN 1668-5180 Resistencia, Chaco

un nivel de ocurrencia de un suceso con una cierta intensidad, en un sitio específico y durante un tiempo de exposición determinado (Cardona, 2001:7).

El proceso erosivo continúa acrecentando la extracción de arena en la playa Danilo, impactando no sólo sobre la base del acantilado sino también, erradicando arena en el fondo marino, desde la orilla hasta la zona de rompiente donde, a diferencia de años anteriores se puede observar afloramientos rocosos en períodos de bajamar. La erosión en la base del acantilado constituye una amenaza porque el desmoronamiento del acantilado en cualquier momento del año, que puede herir a personas que se encuentren en la playa.

La presencia de la escollera en "L" (figura 1) también es una amenaza para la actividad local y turística ya que, se encuentran rocas considerablemente grandes en el lugar y que pueden lastimar a grandes y chicos mientras realizan sus caminatas o para los usuarios de playa cuando realizan actividades recreativas en el mar o en la cercanía de la orilla, debido a que pueden sufrir lesiones en el cuerpo a causa del choque con rocas.

Con respecto a las posibles amenazas que prevalecen en la playa Sun Rider, cabe destacar que las corrientes de rip se han potenciado con la construcción de la escollera, generando un problema mayor para los bañistas ya que todos son posibles candidatos a padecer un momento traumático y ahogarse. Si bien, el acantilado en esta playa se encuentra estable, cabe destacar que fue aquí donde se arrasó con el mismo para construir una bajada de camiones (figura 2) donde pueden existir desmoronamientos posteriores.

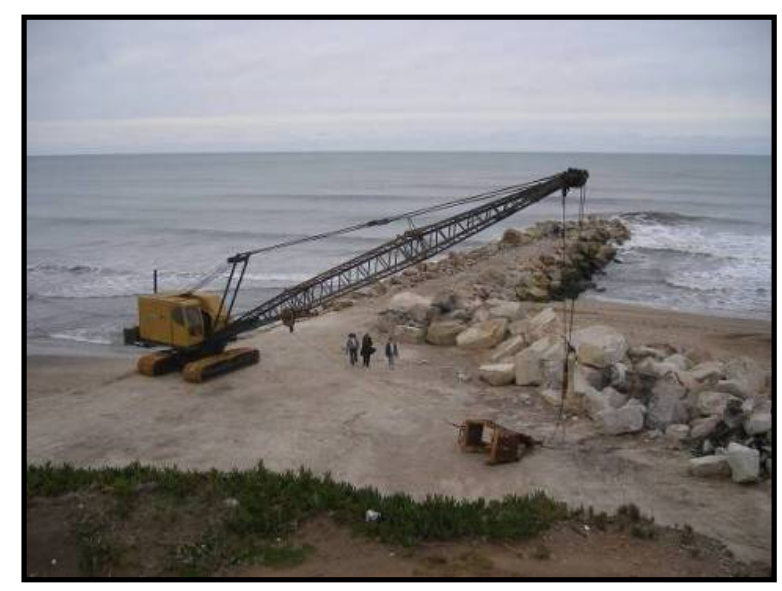

Figura 1. Construcción de la escollera en L, marzo de 2008.

Fuente: archivo personal

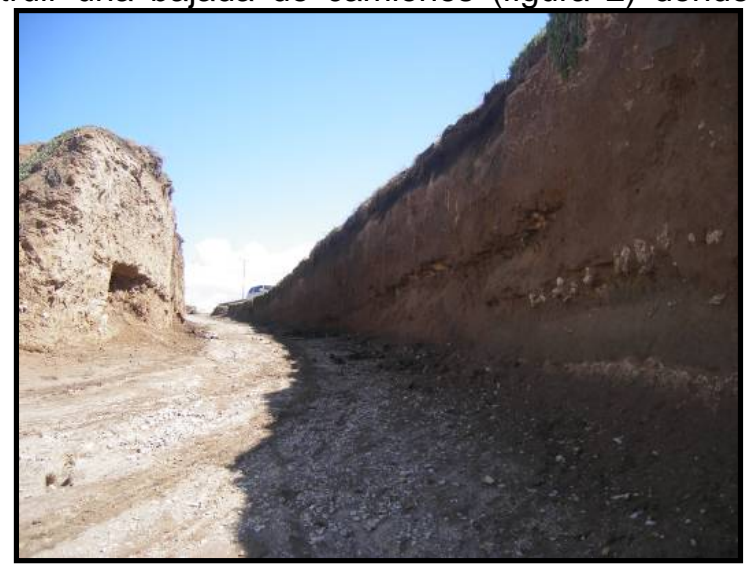

Figura 2. Bajada de camiones en playa Sun Rider. Fuente: archivo personal. 25/03/2010

La peligrosidad es la probabilidad de ocurrencia de un fenómeno físico, tanto natural como tecnológico, que puede presentarse en un sitio específico y en un tiempo determinado, produciendo efectos adversos en personas, bienes o su medio ambiente (Cardona, 1993:16). Para Monti (2007) la fuente de origen de la peligrosidad puede ser natural, inducida (natural o antrópica), tecnológica. Claros son los ejemplos que se pueden vislumbrar a causa de dicha clasificación: en las playas de la 
unidad de estudio la erosión natural está dada por la acción eólica y marina, mientras que la inducida (antrópica) y tecnológica se encuentra relacionada con la presencia de estructuras de roca y cemento en la playa, tales como las escolleras y las escaleras donde se destruyó parte del acantilado para la construcción de las mismas.

La vulnerabilidad por su parte, puede definirse como una predisposición intrínseca a ser afectado o ser susceptible, tanto un sujeto o un grupo de elementos, a sufrir un daño. Esta vulnerabilidad puede ser física, ecológica, social, económica, política, institucional, etc. (Cardona, 1993:17, 2003; Wilches- Chaux, 1993:6).

En las playas estudiadas, una de las vulnerabilidades identificadas es ecológica, porque el modelo de desarrollo costero implementado no se basa en la convivencia, sino en la dominación por destrucción de los recursos del ambiente. Esto conduce a ecosistemas vulnerables, incapaces de autoajustarse internamente para compensar los efectos directos o indirectos de la acción humana y a la vez, riesgosos para las comunidades que los explotan, habitan o disfrutan (Wilches- Chaux, 1993).

Asimismo, se observa una vulnerabilidad institucional, porque los mecanismos de contratación, el manejo del presupuesto, la administración de los funcionarios públicos y, en general, todos sus procedimientos, parecen encaminados a impedir la respuesta estatal ágil y oportuna ante los cambios acelerados del entorno económico, político y social y del entorno ecológico.

Lo antedicho se sintetiza en la cuadro 1. Tal como lo señala Monti (2007), las causas de fondo se relacionan con la distribución de poder en la sociedad donde se destacan factores tales como estructuras y recursos impulsados el gobierno provincial y nacional (escala nacional y regional). La disponibilidad de recursos económicos no ha sido orientada hacia una solución sustentable e integradora que sea determinante para la atenuación de los problemas ambientales relacionados con la contaminación y erosión de la costa marplatense.

La inversión de nuevos fondos para el desarrollo de políticas de tecnologías duras ha sido funcional a ideas arcaicas que hoy en día resultan obsoletas para detener las diferentes problemáticas que interactúan en el litoral. Esto ha favorecido al desarrollo de las presiones dinámicas que se plasman en esta porción del territorio, donde las mismas canalizan causas de fondo en formas particulares de inseguridad. 


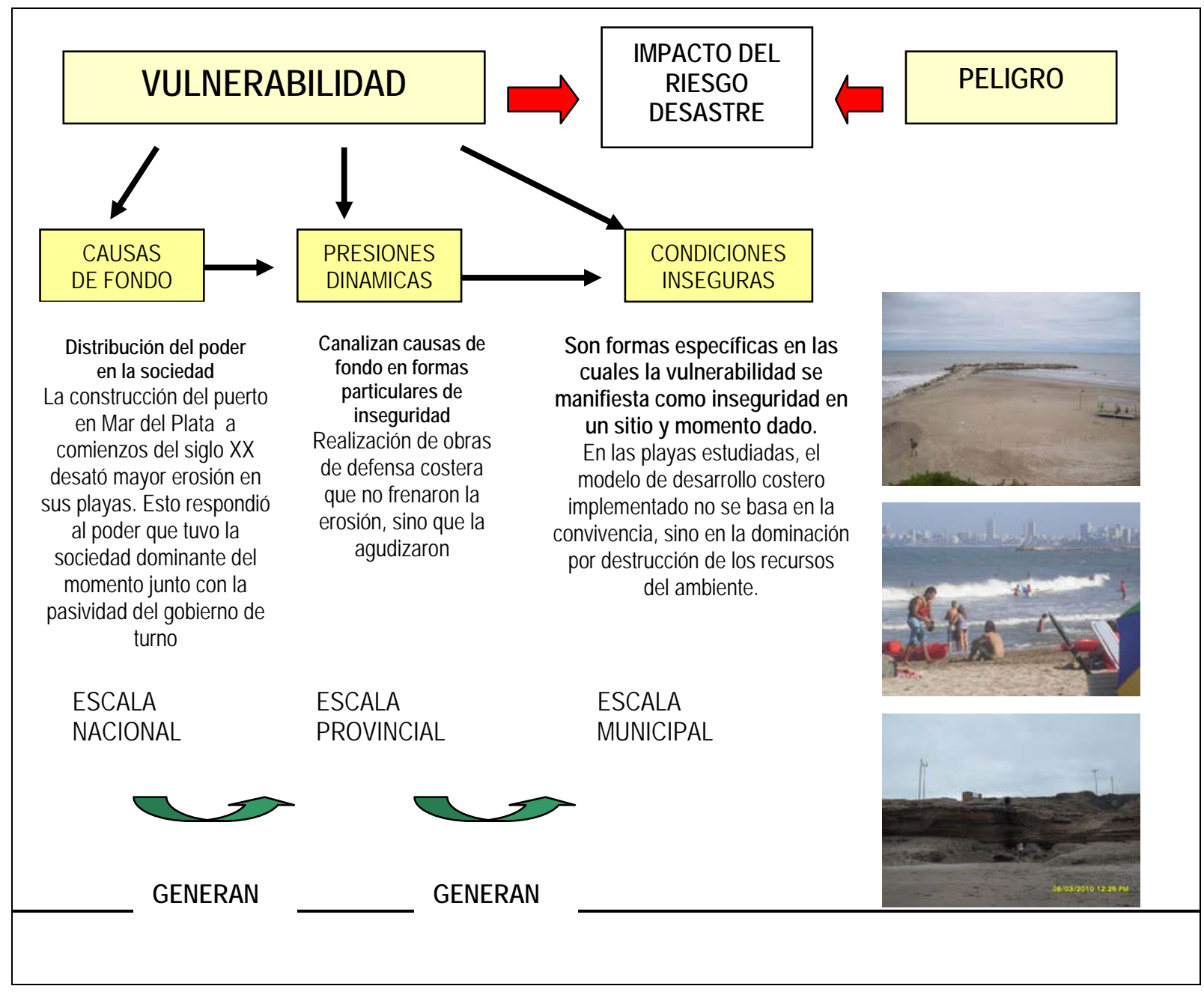

Cuadro 1: Vulnerabilidad. Causales y escalas

Fuente: Adaptado de Monti (2007)

Llevado a una escala local, la pasividad de algunas organizaciones sociales ha contribuido al crecimiento de dichas presiones dinámicas. Estas organizaciones no se han manifestado de ninguna manera: ni en forma legal ni tampoco orientando de forma educativa a la población con respecto a cuál sería la verdadera problemática del sector.

Durante el período estival la presión del turismo se acrecienta, generando una mayor contaminación en las playas. El continuo crecimiento de las presiones dinámicas es propicio para el advenimiento de condiciones inseguras, las cuales son formas específicas de vulnerabilidad que se manifiesta como inseguridad en un sitio y momento dado.

La vulnerabilidad manifestada en esta causalidad se encuentra enmarcada dentro de la escala local, donde el ambiente físico es frágil: los acantilados en estado de retroceso en playa Danilo (figura 3) se encuentran en peligro de derrumbe, además la infraestructura de roca dispuesta como las escolleras, también se está degradando a partir del avance del mar. A raíz de este proceso, los 
turistas y vecinos de la zona son propensos a padecer esta situación de vulnerabilidad debido a la ineficacia de políticas públicas como la falta de preparación para el desastre y el posible predominio de enfermedades infectocontagiosas durante la temporada de verano, debido al incremento de contaminación de las aguas marinas por parte de la planta de efluentes cloacales y los pluviales que vuelcan sus residuos a la playa. Todas estas causalidades generan un escenario del riesgo, que si continúa puede devenir en desastre.

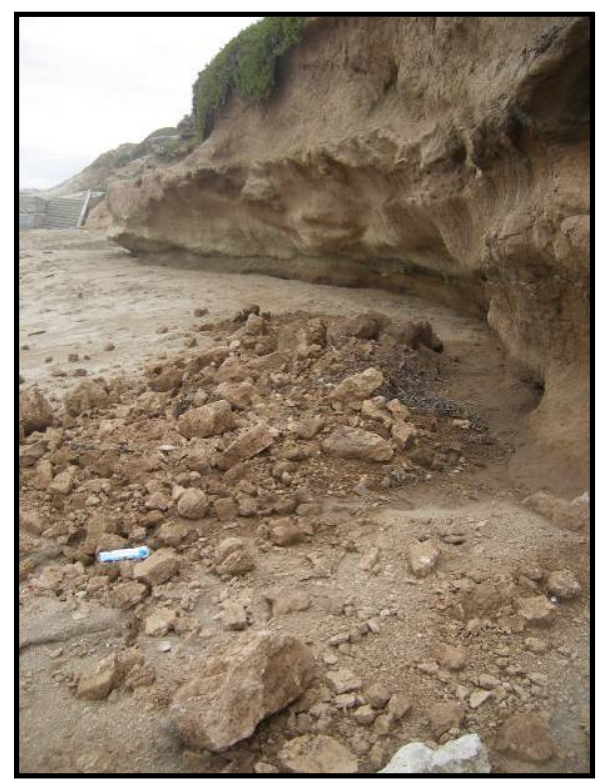

Figura 3. Acantilado en playa

Danilo. Fuente: archivo personal. 25/03/2010

Por su parte, el riesgo se relaciona con la probabilidad de que se manifiesten ciertas consecuencias por la acción de dicho evento. Se refiere al contexto social, material $y$ ambiental representando por las personas y por los recursos y servicios que pueden verse afectados por la ocurrencia de un evento de peligro (Cardona, 1993). Para ONAE (1987) es el grado de pérdidas previstas en vidas humanas, personas lesionadas o heridas, pérdidas materiales y perturbaciones de la actividad económica debidas a un fenómeno determinado.

En el área de estudio, la manifestación del riesgo puede aclararse con la siguiente cadena explicativa (cuadro 2) Las condiciones desfavorables de las causas de fondo, en este sentido, han sido la erosión aguda de la playa Danilo a causa de la disposición de la escollera en "L". Esta presión dinámica provocó con el correr del tiempo afloramientos rocosos entre la zona de rompiente y la orilla y además generó un aceleramiento en las corrientes de rip, no solo en Danilo sino también, en Sun Rider propiciando condiciones inseguras para los bañistas con la posibilidad de causar un riesgo o desastre (entrevista realizada al guardavidas Cristian Di Marco).

Las causas de fondo planteadas en el cuadro 1 se refieren principalmente a la génesis de la erosión en la ciudad, a partir de la construcción del puerto junto con sus dos escolleras que lo protegen de la embestida de los vientos, que obstaculizó la corriente de deriva litoral, principal contribuyente de sedimentos y arena en las playas del centro y norte de la ciudad. Durante la primera mitad del siglo XX que fue cuando se edificó el puerto, solo se conocía un tipo de tecnología que servía para frenar la erosión; las estructuras de roca dispuestas perpendiculares a la línea de costa.

Los proyectos aprobados por la Provincia para realizar obras de defensa costera (estructuras duras) continuaron durante todos estos años, aunque sin ningún éxito en frenar de forma definitiva los procesos erosivos en la costa marplatense. A pesar de que es palpable esta situación, ninguno de los gobiernos de turno a escala provincial y municipal han incursionado en la aplicación de nuevas 
tecnologías, las mismas como ha quedado demostrado en otros países, pueden convivir con la naturaleza sin necesidad de dañarla (Black, 2000) y contribuir a la solución de los problemas ambientales como en este caso la erosión.

\section{CADENAS EXPLICATIVAS DE RIESGOS EN LAS PLAYAS DANILO Y SUN RIDER (MDP)}
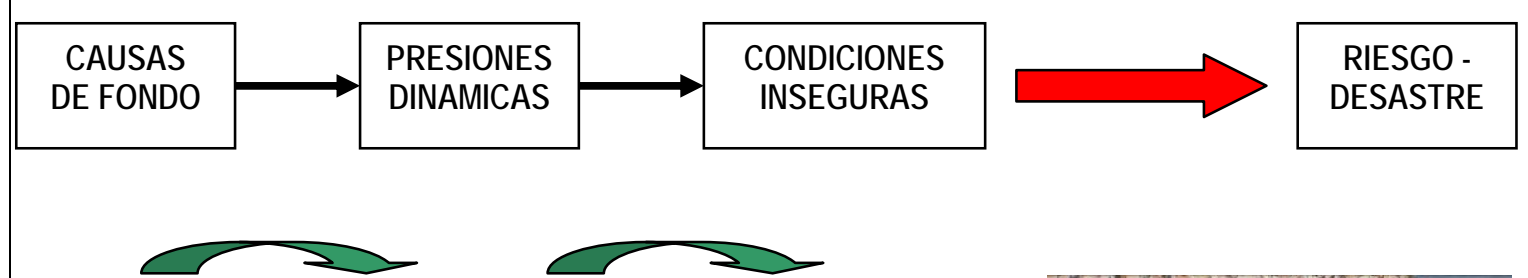

\section{Erosión costera Degradación del manifestada desde la construcción del puerto de Mar del Plata acantilado y la playa, vertidos y usos competitivos de los recursos costeros}

Peligro de derrumbe de sectores de acantilados en el área de estudio y rocas diseminadas por efectos de erosión marina y antrópica
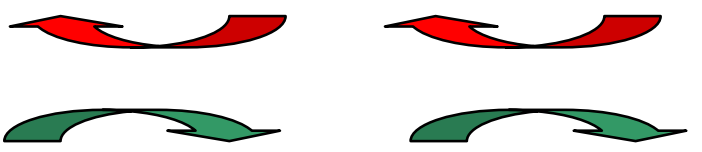

Falta de conocimiento de vecinos y autoridades, sobre nuevas tecnologías de protección y manejo costero

\section{Posible riesgo} epidemiológico a raíz de los problemas de contaminación que padece el sector
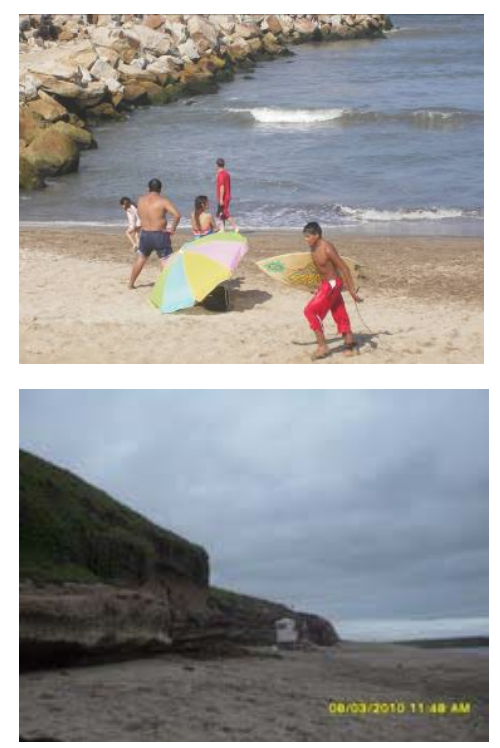

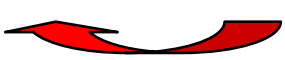

Cuadro 2: Cadenas explicativas de riesgos en el área de estudio Fuente: Adaptado de Monti (2007)

Las presiones dinámicas en el sector se agravan a medida que pasa el tiempo. Los vertidos volcados por la Planta de Tratamiento de Efluentes Cloacales $^{1}$ (figura 4) llegan hasta las costas de las playas estudiadas, y con mayor periodicidad durante el verano. A esto debe sumarse el agua de lluvia junto con restos de basura que bañan las playas a través de los pluviales.

Estas problemáticas ambientales crean condiciones inseguras en el espacio costero como peligro de derrumbes, ocasionando lesiones en las personas además de la ocurrencia de un posible riesgo epidemiológico a partir de la contaminación de las aguas y playas. Esta exposición hace

\footnotetext{
${ }^{1}$ Cabe destacar que en la actualidad se está construyendo el Emisario submarino que será localizado donde se encuentra la actual Planta de Tratamientos de Efluentes Cloacales, en la zona norte de Mar del Plata.
} 
Revista Geográfica Digital. IGUNNE. Facultad de Humanidades. UNNE. Año 8. № 16. Julio - Diciembre 2011. ISSN 1668-5180 Resistencia, Chaco

vulnerables a la población y bienes, debido a la ineficacia de políticas públicas como la falta de preparación para el desastre y el posible predominio de enfermedades infectocontagiosas durante la temporada de verano, debido al incremento de contaminación de las aguas costeras por parte de la planta de efluentes cloacales y los pluviales que vuelcan sus residuos a la playa (Pérez Guzzi, 2006).

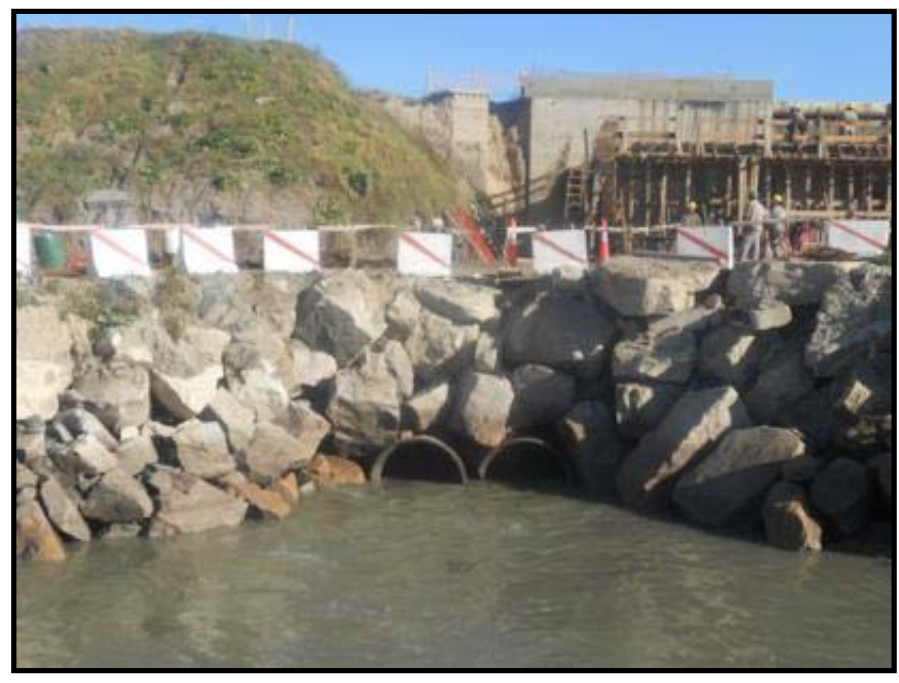

Figura 4. Descarga de la Planta de Tratamiento de Efluentes Cloacales. Fuente: archivo personal. 19/05/2010

El proceso que conduce a la identificación de los riesgos tiene como punto de partida la detección y evaluación de los peligros, teniendo en cuenta que el riesgo es la probabilidad de ocurrencia de un peligro. El análisis del riesgo permite avizorar la probabilidad de pérdidas de vidas o de bienes materiales, por ello es un concepto estrechamente asociado a la noción de vulnerabilidad, la cual implica una condición de debilidad o desprotección que poseen los individuos pudiendo sufrir perjuicios personales, sobre sus pertenencias o sobre los espacios involucrados.

Detectar, localizar y analizar los peligros es la tarea central en la geografía de los riesgos. La lucha cotidiana contra el peligro tiene su máxima expresión en el manejo del riesgo. Organizar un conjunto de medidas que eviten la ocurrencia del peligro o bien reducir al máximo sus efectos, pasa a ser el objetivo final de estos estudios. La ignorancia del peligro es el principal factor de su agravación.

Morello (1993), señala que alguna de las estrategias adoptadas, pasan por uno de los siguientes tipos de ajuste:

a) No hacer nada, conviviendo con el riesgo de manera continua; tal como ocurre en las zonas de mayor vulnerabilidad, como por ejemplo, los usuarios que utilizan las playas del área de estudio a pesar de los peligros de derrumbe del acantilado, lar rocas de la defensa costera o la contaminación de las aguas.

b) Modificar el impacto de las pérdidas, como por ejemplo, el resarcimiento ate un accidente producido en el área por los motivos antes señalados. No obstante, el problema es complejo, ya que el diseño de la ayuda debe ser precisa; de lo contrario, si el sistema de alivio y asistencia no es 
Revista Geográfica Digital. IGUNNE. Facultad de Humanidades. UNNE. Año 8. № 16. Julio - Diciembre 2011. ISSN 1668-5180 Resistencia, Chaco

adecuadamente manejado, puede estimular la ocupación de espacios de alto riesgo y la dependencia del asistencialismo.

c) Modificar la susceptibilidad al daño, mediante la regulación del uso de la tierra y una apropiada legislación y control por parte del Estado, situación que hasta ahora tiene escasa aplicación, por ejemplo, restringiendo el baño o la pesca en determinadas áreas expuestas

d) Modificar el riesgo o el evento, justificado en el caso de áreas urbanas, tal como ocurre con la construcción del emisario submarino. Aún en esos casos, no se puede garantizar la protección total. Las experiencias han mostrado que algunas actuaciones puntuales sobre la costa, generalmente sólo contribuyen a agravar el problema -como ocurrió con la construcción de la escollera en L - , si no se encaran con un criterio integral que contemple los intereses y racionalidades de todos los actores involucrados (García, 2001)

\section{Conclusiones y propuestas de gestión para el área de estudio}

La información amplía las oportunidades de todos los integrantes de la comunidad. Es a la vez, un bien esencial y un medio muy importante para transferir poder a los habitantes urbanos, para que puedan decidir y actuar en las situaciones riesgosas (García, 2001). Con vistas a ello, el proceso de gestión de riesgos debe orientarse a la realización de un proceso de prevención que pase por las siguientes vertientes:

$\checkmark$ Una gestión de las amenazas o factores desencadenantes del desastre, reduciendo a través de distintas acciones, el impacto de las amenazas físicas. Puede involucrar acciones de prevención estructural - grandes obras - y no estructural - preparación y capacitación de los grupos vulnerables -

$\checkmark \quad$ Una gestión de las vulnerabilidades, mediante la mitigación de la emergencia, asegurando el bienestar y seguridad de los afectados.

$\checkmark$ Una gestión de la rehabilitación y reconstrucción, estableciendo condiciones más apropiadas para la población afectada.

Al considerar el riesgo como un proceso, se supera el tradicional enfoque centrado sólo en la respuesta y en la reconstrucción, para incorporar, como sostienen Barrenechea y Gentile (1996), una idea del "continuo del desastre", el cual tiene en cuenta el conjunto de aspectos que hacen a las condiciones y dinámicas socio - políticas que constituyen las situaciones de riesgo. La gestión de riesgos puede optar entonces, por asumir los mismos como objeto de gestión o revestirlos con carácter de excepcionalidad, implementando estrategias o medidas a tal fin.

Resulta muy importante además tener presente que, los diferentes actores sociales tienen percepciones distintas de la vulnerabilidad y del riesgo y en consecuencia, tener valoraciones y comportamientos distintos frente a ellos. Tampoco conviene descuidar los encuentros y desencuentros de los múltiples actores sociales y sus racionalidades, lógicas e intereses diversos, 
porque ellos serán los que constituyan el punto de partida de los procesos de conformación y gestión de riesgos.

Las posibles soluciones a las cuales se concluye, oscilan principalmente en brindar respuestas a las problemáticas ambientales como la contaminación y la erosión costera, las cuales actúan en este espacio geográfico como las principales promotoras de la vulnerabilidad, amenaza y peligrosidad originando un azaroso escenario de riesgo, además de ser las primordiales en cuanto a generadoras de conflictos entre actores sociales e incompatibilidad de usos. Las nuevas tecnologías junto con un cambio en las políticas ambientales implementadas por el Estado Nacional en sus distintas escalas, vislumbrarían un nuevo escenario para la costa marplatense, menos riesgoso y más sustentable.

\section{Bibliografia}

- Black, K. P., (2000). Arrecifes artificiales para el control y amenidad. Teoría y aplicación. Simposio internacional de costas. (ICS2000). Rotorua, Abril de 2000.

- Cardona O.D. (1993): "Evaluación de la Amenaza, la Vulnerabilidad y el Riesgo", En los Desastres No son Naturales, A. Maskrey (Compilador), LA RED, Tercer Mundo Editores, Bogotá, Colombia.

- Cardona, O. D. (2001). La necesidad de repensar de manera holística los conceptos de vulnerabilidad y riesgo. Una crítica y revisión necesaria para la gestión. Centros de Estudios sobre Desastres y Riesgos. CEDERI. Universidad de Los Andes, Bogotá, COLOMBIA.

- García, M. C. (2001) Percepción de vulnerabilidad ambiental en poblaciones urbanas. Tesis de Maestría Gestión Ambiental del Desarrollo Urbano, Facultad de Arquitectura, Urbanismo y Diseño, Universidad Nacional de Mar del Plata, Mar del Plata, (inédita), julio de 2001.

- Monti, A. (2007). Geoindicadores costeros: conceptos generales y casos de estudio. En: Análisis integral de riesgos costeros. Conceptos, metodologías y casos de estudio. Curso de Posgrado- Universidad Nacional de Mar del Plata, Mar del Plata, 1 al 4 de octubre de 2007.

- Morello, J. (1993). Riesgos, daños y catástrofes. Boletín Medio Ambiente y urbanización. Año 1; no 3-4. Buenos Aires

- $\quad$ ONAE, Presidencia de la República, (1987). Atención de Emergencias. Citado por Wilches Chaux, (1993).

- Pérez Guzzi, J.; Zamora, A. S; Falabella, A. M.; Isla, I. F.; Escalante, A. (2006). Situación sanitaria de la zona balnearia de la ciudad de Mar del Plata, Argentina. $1^{\circ}$ Congreso internacional sobre Gestión y Tratamiento Integral del Agua. Córdoba, Argentina. Abril de 2006.

- Wilches Chaux, Gustavo (1993). La Vulnerabilidad Global. En Maskrey, A. (ed.) Los Desastres no son Naturales. La Red. Tercer Mundo Editores, Colombia 